\title{
Contribuição para o estudo da influência da profundidade de trabalho do arado na produção agrícola
}

\author{
HUGO DE ALMEIDA LEME \\ Professor-Catedrático de Mecânica e Máquinas Agrícolas \\ Escola Superior de Agricultura "Luiz de Queiroz" \\ Universidade de S. Paulo - Piracicaba
}

\section{INDICE}

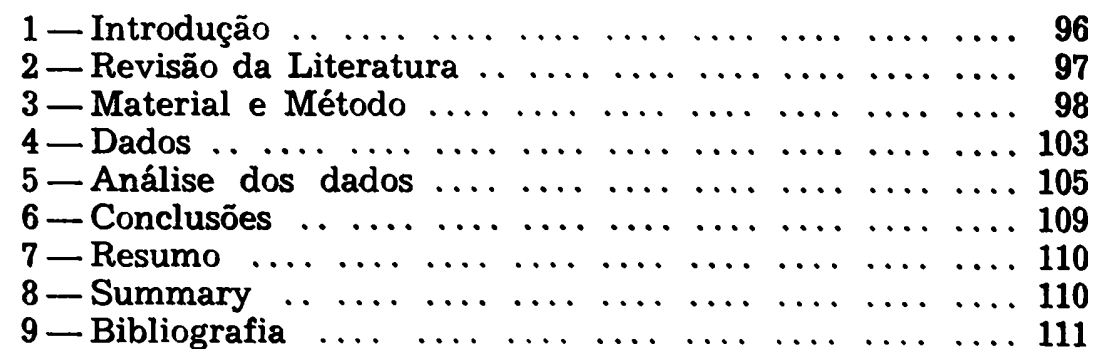




\section{INTRODUÇĀO}

A aradura, não resta a manor dúvida, tem sido a principal das operaçöes agrículas para o desenvolvimento das diversas culcuras. Assim sendo, é evidente que o estudo desta operação, uma das mais primivivas a comuns das práticas agrículas, seja muito desenvolvido.

Os antigos agricultures romanos, (1) sègundo depreendese das cbras Vergilianas, já tinham as suas teorias sôbre aradura e sóbre o modo de realizá-la. Assim, por exemplo, não era cosiume naquele tempo inverter de um modo tão radical as leivas, cumo fazem us modernos aradis. A principal preocupaçảo era, então, quebrar profundamente is s.lo mediante sêgas que formavam o rastrum.

O arado, a mais primitiva das máquinas agrícolas, por êstes mutivcs, foi sempre cbjeto de estudo constante, não sòmente por parte dos agriculiores e fabricantes, como também pelos técnicos do mecánica agriculo, de vez que êle constitui - a máquina indispensável para qualquer cultivo. Desta forma, o simples e elemeniar ramo de árvore, com a ponta endurecida pelo fogo, utilizada para rasgar o solo, foi evoluindo até transformar-se no arado hodierno; seja no aperfeiçnado arado de aiveca, construid:) :m diferentes materiais e dimensōes, formado de corpo cilindrico, helicoidal, parabólico-hiperbólico, ou coninic , de um ou vários corpos, adatável às diversas condiçōes de solos e finalidades; seja, no moderno arado de disco, que com sua diferente constituição, produti de uma evolução, apresenta em confronto ao de aiveca, certas vantagens e desvantagens bem conhecidas.

A história do arado confirma, que a aradura, uma das primeiras práticas agrícolas, foi sempre considerada como a base pira o desenvolvimento da exploração agrícola.

A energia gasla pelo trabalho do arado em tódas as regiōes da terra, é cousa digna de ser apreciada e estudada. Já lienry Ford (2), em seu livrs "Minha vida e minha obra", comenta: " $E$ " maior o gasto de energia consumida na aradura que o de tòdas as indústrias reunidas". Isto ressalta a importância sempre compreendida, do alto valor do estudo dessa máquina.

Considerando todos os motivos expostos, conclui-se que é necessário estudar cum a máxima atenção o arado, não sòmen. te sob o ponto de vista dinamométricn, orgânico ou descritivo, 
como também, e com grande cuidado, sob o ponto de vista agrícola e econômico, encarando-se desta forma a máquina em relação ao aumento de produção agrícola, ou lògicamente o rendimento da máquina em relação à essa produção.

Foi de acôrdo com êsse objetivo que procurámos experimeniar o arado, fazendo-o trabalhar à várias profundidades, a fim de determinar para os diversos tipos de solos, qual a condição de trabalho que apresenta a melhor produção agrícola, - fator básico da agronomia, - para se ter pois a indicação, para a correta aplicação da mais comum das máquinas agrícolas.

Foi visando êste objetivo, repetimos, que procurámos desenvolver a experimentação com o fim de obter dados que orientassem, o melhor emprêgo do arado, e portanto o seu rendimenio, de vez que a aradura, nas nossas condiçōes, faz-se sempre superficiais.

\section{REVISÃO DA LITERATURA}

Procurando esclarecer o assunto, examinemos a literatura a respeito, e assim encontraremos em :

Conti, Marcelo (1), pág. 10 - "As araduras no sentido amplo da palavra, têm o objetivo preparar a terra para os cultivos, assim como o cuidado das plantas, ou bem o armazenamento e conservação da umidade do solo".

"Referindo-se agora tão sòmente às araduras, de preparação do solo, que se denominam também fundamentais, recordamos que nos textos clássicos da matéria, acostuma-se dividilas em trabalhos superficiais, ordinários, profundos e de desfundamentos. Em relação à profundidade que alcança cada um dêstes tipos de trabalho, diremos que ela varia segundo os países, e em grau mais ou menos intensivo e racional de sua agricultura. Referindo-se às nossas práticas locais, observamos que as ditas profundidades apresentam os valores seguintes:

a) araduras superficiais: as que não passam de 8 a $10 \mathrm{~cm}$;

b) araduras ordinárias: as compreendidas entre $12-18 \mathrm{~cm}$;

c) araduras profundas: as compreendidas entre 20-35-cm;

d) araduras desfundamento: as superiores a $40 \mathrm{~cm}$.

Os modernos conhecimentos sôbre a ciência do solo têm demonstrado em forma terminante, ratificando com isto e com métodos mais modernos de investigações, o que desde tempos imemorais sabe todo bom agricultor, que tem uma importân- 
cia fundamental sôbre a vida e o desenvolvimento das plantas o tempo, o modo e a forma em que foi realizada a aradura.

Com efeito, nunca se deve esquecer que até os solos mais férteis e melhor adubados podem ver-se notadamente prejudicados, e às vêzes por vários anos em suas aptidões produtivas, devido a uma inoportuna ou má aradura. Porém, desgraçadamente, êstes conceitos que repetimos, conhecidos desde os tempos de Vergílio e Columela, são frequentemente esquecidos, e sòmente os aplicam os agricultores inteligentes que conhecem o exercício da profissão", e ainda

"Com relação aos trabalhos profundos, Yermoloff, estudou - caso das terras negras da Rússia, para as quais uma aradura muito profunda resulta prejudicial. Parece, segundo êsse agrônumo, que com isto altera-se o estado de coesão, a atividade microbiana, e a delicada estrutura coloidal destas terras tão distintas das demais".

\section{MATERIAL E MÉTODO}

3.1 - Material. Após estudo prévio, ficou estabelecido que o ensaio seria desenvolvido num terreno da Escola Superior de Agricultura "Luiz de Queiroz", pertencente à 11a. Cadeira (Química Agrícola), sendo o mesmo mais ou menos plano e homogêneo.

3.1.1 - Solo. O terreno, que estava sem ser trabalhado há alguns anos, apresentava-se coberto de capim favorito (Banicum Teneriffae R. Br.), capim gordura (Penicum melinis, Trin.), capim fino (Panicum purpurascens, Raddi), em predominância, sendo necessário, para a sua utilização, sofrer um preparo prévio, que foi uniforme a todo o bloco.

Quanto às características do solo aluvião arenoso, examinadas, foram as seguintes, de acôrdo com Ranzani (3).

\section{Caracteristicas Físico-Mecânicas}

\begin{tabular}{|c|c|c|c|c|}
\hline $\begin{array}{l}\text { undidade }(\mathrm{cm}) \text { (Prof. (cm) } \\
\text { sidade real (Dr.) } \\
\text { sidade aparente }(\mathrm{Da}) \\
\text { sidade aparente/densidade }\end{array}$ & $\begin{array}{r}0--5 \\
2,84 \\
1,65\end{array}$ & $\begin{array}{c}5-15 \\
2,50 \\
1,65\end{array}$ & $\begin{array}{r}15--30 \\
2,51 \\
1,44\end{array}$ & $\begin{array}{r}30--70 \\
2,48 \\
1,46\end{array}$ \\
\hline $\begin{array}{l}\text { real (Da } \\
\text { or (úmido) } \\
\text { or (sêco) }\end{array}$ & & $\begin{array}{r}0, \\
5 \mathrm{YR} \\
5 \mathrm{YR}\end{array}$ & $\begin{array}{r}0 \\
5 Y \mathrm{Y}\end{array}$ & \\
\hline
\end{tabular}


Análise Mecânica

Areia grossa \% pêso (A gr \% pêso)

Areia grossa \% vol. (A gr \% vol.)

Areia fina $\%$ pêso (Af $\%$ pêso)

$36,5 \quad 35,5 \quad 33,0 \quad 26,0$

Areia fina $\%$ vol. (Af $\%$ vol.)

Limo \% pêso (L \% pêso)

Limo \% vol. (L \% vol.)

Argila \% pêso (Árg \% pêso)

Argila \% vol. Arg \% vol.)

Classificação testural (Classif. testural)

$21,2 \quad 21,3 \quad 18,8 \quad 15,3$

$\begin{array}{llll}48,5 & 47,5 & 47,0 & 49,0\end{array}$

$28,1 \quad 33,5 \quad 27,4 \quad 28,9$

$\begin{array}{llll}4,0 & 5,0 & 4,0 & 3,0\end{array}$

$2,3 \quad \because, 3 \quad 2,3 \quad 1,8$

$11,0 \quad 12,0 \quad 16,0 \quad 23,0$

$\begin{array}{rrrr}6,4 & 7,9 & 9,1 & 13,5\end{array}$

LA LA LA LA

Consistência (estado úmido)

Limite Superior ou limite de Liquidez (L.L. \%)

Limite inferior de plasticidade ou limite de plasticidade (L.P. \%)

Número de índice de plasticidade (I.P. \%)

Indice de escoamento (I.E.)

Indice de tenacidade (I.T. \%)

$19,0 \quad 19,0 \quad 21,5 \quad 21,8$

$15,3 \quad 14,4 \quad 13,8 \quad 11,5$

$\begin{array}{rrrr}3,7 & 4,6 & 7,7 & 10,3 \\ 4,0 & 7,3 & 5,0 & 9,4\end{array}$

$\begin{array}{llll}0,93 & 0,63 & 1,54 & 1,09\end{array}$

Fase Líquida

Agua capilar máxima (A \%)

Higroscopia \% pêso (Hy \% pêso)

Higroscopia \% vol. (Hy \% vil.)

Umidade de murchamento \% pêso ( $\mathrm{U} \mathrm{mu} \%$ pêso)

Umidade de murchamento \% vol. (U mu \% vol.)

Umidade equivalente \% pêso U eq \% pêso)

Umidade equivalente \% vol. (U eq \% vol.)

Agua capilar máxima em \% pêso ( $\mathrm{A} \%$ pêso)

Agua capilar máxima em \% vol. ,A \% vol.)

Ascenção capilar máxima (hT)

Velocidade máxima de ascenção capilar (Vh)

Altura máxima de água absorvida $(\mathrm{HT})$

$\begin{array}{lllr}0,78 & 0,94 & 0,92 & 1,11 \\ 2,1 & 2,1 & 2,2 & 2,8 \\ 3,5 & 3,5 & 3,2 & 4,1 \\ 5,8 & 5,5 & 5,6 & 7,0 \\ 9,6 & 9,1 & 1 \mathbf{8 , 1} & .10,2\end{array}$

$18,5 \quad 18,0 \quad 18,3 \quad 10,3$

$14,0 \quad 13,2 \quad 11,9 \quad 15,0$

$20,9 \quad 21,3 \quad 23,5 \quad 24,3$

$34,5 \quad 35,2 \quad 33,8 \quad 35,5$

$511,3 \quad 546,7 \quad 412,6 \quad 555,1$

$55,84 \quad 88,7 \quad 59,4 \quad 68,5$

$\begin{array}{llll}142,1 & 162,0 & 132,7 & 251,7\end{array}$ 
Velocidade máxima de absorsāo (VH)

Coeficiente de permeabilidade hidráulica (Ks) $19,44 \quad 31,32 \quad 14,65 \quad 40,84$ $\begin{array}{llll}4,05 & 4,79 & 3,50 & 2,83\end{array}$

\section{Fase Gasosa}

Ar natural (Ar nat.) Porosidade natural (P nat.) Porosidade minima ou volume mínimo de poros (P min.) Porosidade relativa (P rel.)

$\begin{array}{rrrr}26,6 & 18,4 & 24,2 & 25,1 \\ 41,9 & 34,0 & 42,6 & 41,1 \\ 44,3 & 35,4 & 35,5 & 37,7 \\ 0,9 & 1,0 & 1,2 & 1,1\end{array}$

\section{Caracteristicas Quimicas}

$\mathrm{pH}-5,5 ; \mathrm{C}$ (carbono) - $1,2 \% ; \mathrm{N}$ (total) - 0,08\%; $\mathrm{P}$ trocável) $\mathrm{PO}^{4}$ - -) 0,18 milieq/100g; $\mathrm{K}$ trocável $(\mathrm{K}+)-$ 0,06 milieq $/ 100 \mathrm{~g}$; $\mathrm{Ca}$ trocável $(\mathrm{Ca}++)-3,1$ milieq100/g -; $\mathrm{Mg}$ trocável $(\mathrm{Mg}++)-0,70 \mathrm{milieq} / 100 \mathrm{~g} ;$ Bases trocáveis (S) 6,5 milieq/100g.

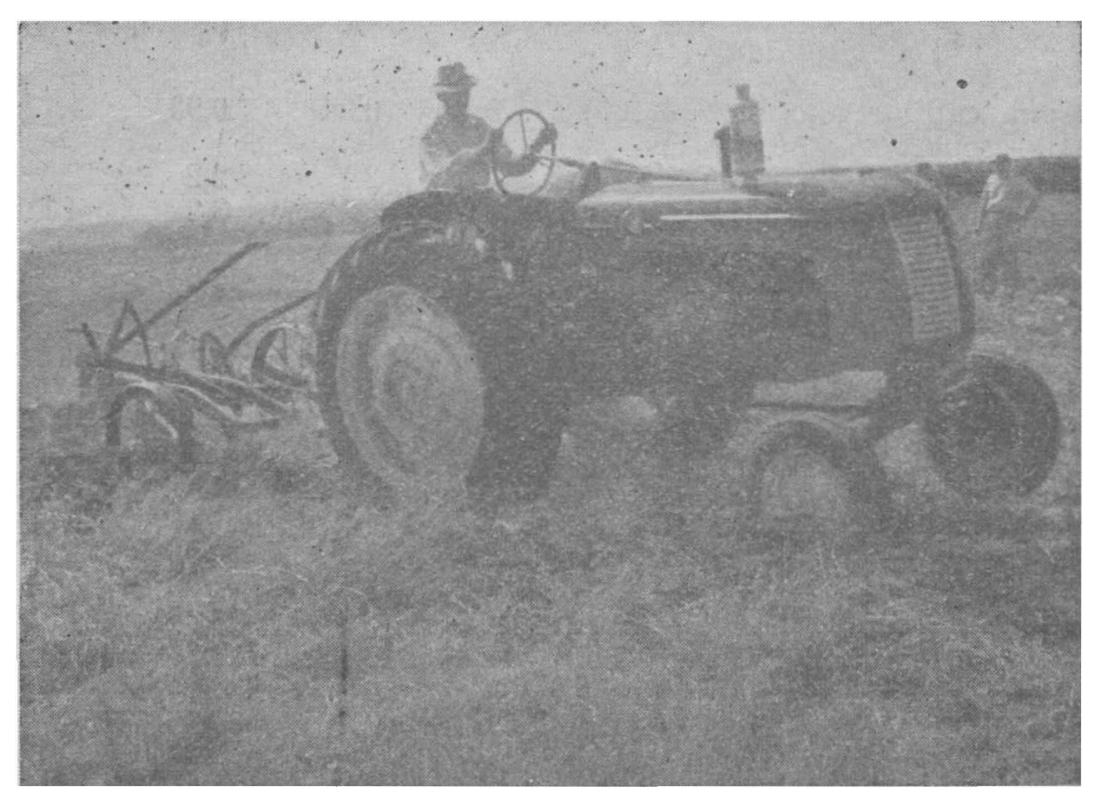


3.1.2 - Máquinas. A aradura do terreno foi realizada com auxílio de um (a) arado Allis Chalmers n. 2-2-4, de duas aivecas, o qual era devidamente regulado antes de ser colocado sôbre o canteiro, na profundidade desejada.

(b) No terceiro ano de experiência um novo tratamento foi realizado, isto é, o terreno foi subsolado à profundidade de $40 \mathrm{~cm}$, com um subsolador Killefer 20A (2010-D.)

(c) O trator utilizado para a experimentação foi um Cockshutt 40 , de roda de peneumáticos, com chassis standard, provido de seis velocidades para a frente e duas contra-marchas, motor Buda, de gasolina, de 6 cilindros e 1.650 r.p.m. De acôrdo com o teste de Nebraska, n. 442, extraído do Red Tractor Book (4), a potência máxima observada na polia do trator é de $43,3 \mathrm{HP}$, dando como máxima corrigida $45,59 \mathrm{HP}$, sendo a potência máxima observada na barra de tração $40,06 \mathrm{HP}$ e corrigida 37,85 HP (Fig. 1).

3.2 - Método. Escolhido o terreno foi o mesmo gradeado a fim de eliminar a vegetação que existia.

O tipo de experimentação escolhido, foi de estabelecer canteiros de $50 \times 20 \mathrm{~m}$ para facilitar o trabalho com as máquinas, e êsses canteiros em número de 28 , foram sorteados para a sua distribuição. Para a perfeita distribuição, os canteiros foram separados de $2 \mathrm{~m}$ entre as linhas e $4 \mathrm{~m}$ de ruas. Conforme se depreende do exposto, deu-se 4 repetições para cada tratamento (Fig. 2).

No terceiro ano de experiência foi feito um tratamentc. com subsolagem a $40 \mathrm{~cm}$ e aradura a $30 \mathrm{~cm}$, sendo que no segundo ano o terreno foi tratado com um adubo composto para melhor constatar o resultado.

Antes da aradura de cada terreno à diferente profundidade,o arado era regulado fora do terreno, e uma vez obtida a profundidade desejada, procedia-se à aradura dos diversos canteiros, sempre com o devido contrôle (Figs. 1 e 3).

A disposição dos canteiros, é evidente que permaneceu sempre a mesma, de acôrdo com o planejamento da experiência.

Nos canteiros trabalhades nas diversas profundidades, foi semeado milho, por ser uma cultura bastante comum, e de perfeito contrôle.

Após o desenvolvimento da cultura, que era tratada de maneira usual, o milho era colhido em rama. Para êste fim os operários cortavam com um facão o pé de milho junto ao solo. Uma vez pesada a rama, destacavam e pesavam as espigas. Em cada canteiro, as pesagens eram feitas separadamente. 


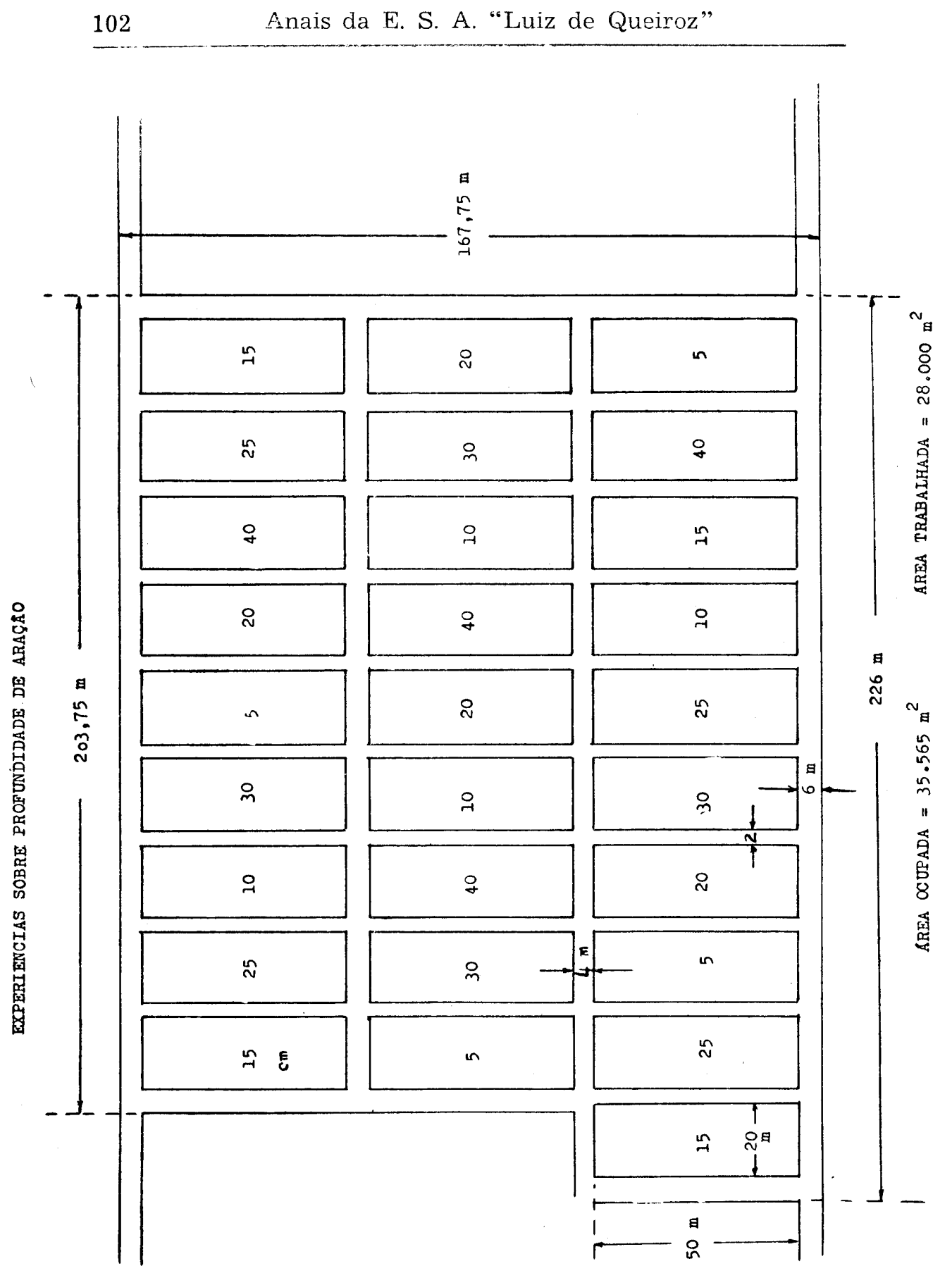




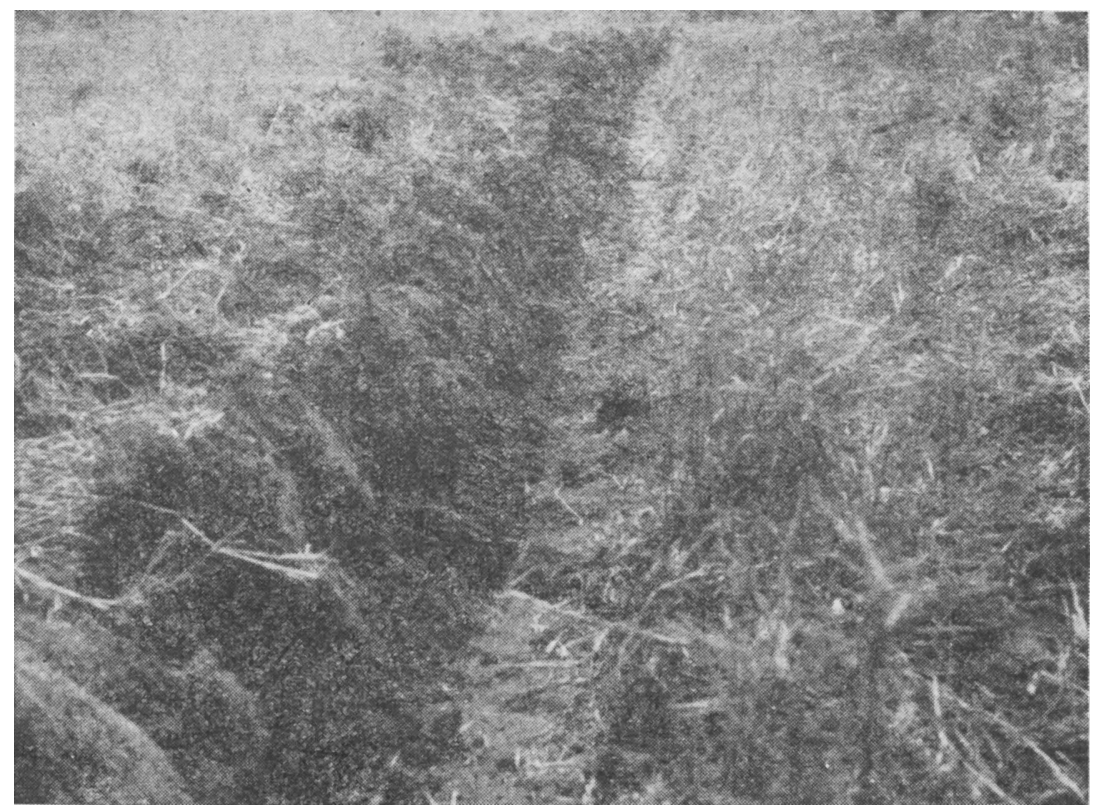

As espigas, colocadas em sacos, devidamente etiquetados, eram, a seguir, debulhadas, obtendo-se o pêso do milho debulhado de cada canteiro. Assim procedia para se avaliar a produção do milho debulhado de cada canteiro. Assim procedia para se avaliar a produção do milho em rama, em casca e debulhado, a fim de se obter melhor resultado da produção.

\section{DADOS}

Após o desenvolvimento da experiência, colhido e pesado 0 produto, foram obtidos os seguintes resultados, para os diversos anos :

$\mathrm{Na}$ experiência 1950-51.

$\begin{array}{rrccc}\text { Canteiros } & \begin{array}{c}\text { Milho em Rama } \\ \text { (Em Kg) }\end{array} & \begin{array}{c}\text { Em Casca } \\ \text { (Em Kg) }\end{array} & \begin{array}{c}\text { Debulhado } \\ \text { (Em Kg) }\end{array} \\ \text { 5. A } & 169,800 & 96,000 & 43,300 \\ \text { 5 } & \text { B } & 199,600 & 93,000 & 45,000 \\ \text { 5 } & \text { C } & 173,500 & 86,510 & 42,500 \\ \text { 5 } & \text { D } & 162,400 & 76,100 & 39,000\end{array}$



Anais da E. S. A. "Luiz de Queiroz"

$\begin{array}{rlrrr}10 & \text { A } & 248,600 & 139,800 & 68,000 \\ 10 & \text { B } & 218,500 & 111,000 & 56,000 \\ 10 & \text { C } & 149,500 & 79,000 & 31,000 \\ 10 & \text { D } & 139,100 & 86,400 & 38,000 \\ & & & & \\ 15 & \text { A } & 309,800 & 174,400 & 87,000 \\ 15 & \text { B } & 192,000 & 104,500 & 50,000 \\ 15 & \text { C } & 280,000 & 113,800 & 61,100 \\ 15 & \text { D } & 253,600 & 104,500 & 50,000 \\ & & & & \\ 20 & \text { A } & 493,450 & 247,400 & 141,000 \\ 20 & \text { B } & 272,500 & 147,100 & 75,500 \\ 20 & \text { C } & 399,000 & 223,000 & 129,500 \\ 20 & \text { D } & 173,400 & 136,600 & 78,000 \\ & & & & \\ 25 & \text { A } & 509,700 & 274,350 & 159,000 \\ 25 & \text { B } & 175,300 & 85,500 & 48,300 \\ 25 & \text { C } & 404,150 & 228,000 & 131,500\end{array}$

Superfície de cada canteiro $1.000 \mathrm{~m}^{2}$.

\begin{tabular}{|c|c|c|c|c|}
\hline Cantei & iros & $\begin{array}{c}\text { Milho em Rama } \\
\text { (Em Kg) }\end{array}$ & $\begin{array}{l}\text { Em Casca } \\
(\mathrm{Em} \mathrm{Kg})\end{array}$ & $\begin{array}{l}\text { Debulhado } \\
\text { (Em Kg) }\end{array}$ \\
\hline $\begin{array}{l}5 \\
5 \\
5 \\
5\end{array}$ & $\begin{array}{l}\mathrm{A} \\
\mathrm{B} \\
\mathrm{C} \\
\mathrm{D}\end{array}$ & $\begin{array}{l}140,000 \\
231,200 \\
327,000 \\
149,800\end{array}$ & $\begin{array}{r}66,000 \\
96,600 \\
146,000 \\
67,400\end{array}$ & $\begin{array}{l}41,800 \\
69,200 \\
90,400 \\
63,600\end{array}$ \\
\hline $\begin{array}{l}10 \\
10 \\
10 \\
10\end{array}$ & $\begin{array}{l}\text { A } \\
\text { B } \\
\text { C } \\
\text { D }\end{array}$ & $\begin{array}{l}536,800 \\
331,200 \\
281,400 \\
234,400\end{array}$ & $\begin{array}{l}147,800 \\
150,000 \\
128,300 \\
102,400\end{array}$ & $\begin{array}{l}89,800 \\
87,200 \\
74,200 \\
\mathbf{8 1}, 700\end{array}$ \\
\hline $\begin{array}{l}15 \\
15 \\
15 \\
15\end{array}$ & $\begin{array}{l}\text { A } \\
\text { B } \\
\text { C } \\
\text { D }\end{array}$ & $\begin{array}{l}560,000 \\
174,000 \\
148,000 \\
324,000\end{array}$ & $\begin{array}{r}171,000 \\
82,000 \\
91,400 \\
137,000\end{array}$ & $\begin{array}{r}106,100 \\
48,300 \\
55,600 \\
81,400\end{array}$ \\
\hline $\begin{array}{l}10 \\
20 \\
20 \\
20\end{array}$ & $\begin{array}{l}\mathrm{A} \\
\mathrm{B} \\
\mathbf{C} \\
\mathrm{D}\end{array}$ & $\begin{array}{l}330,500 \\
442,700 \\
167,600 \\
243,000\end{array}$ & $\begin{array}{r}128,900 \\
204,600 \\
88,000 \\
115,000\end{array}$ & $\begin{array}{r}82,100 \\
111,300 \\
55,200 \\
70,000\end{array}$ \\
\hline $\begin{array}{l}25 \\
25 \\
25 \\
25\end{array}$ & $\begin{array}{l}\text { A } \\
\text { B } \\
\text { C } \\
\text { D }\end{array}$ & $\begin{array}{l}487,000 \\
242,000 \\
183,800 \\
317,000\end{array}$ & $\begin{array}{r}180,000 \\
127,000 \\
80,000 \\
135,000\end{array}$ & $\begin{array}{r}83,000 \\
105,500 \\
48,000 \\
79,800\end{array}$ \\
\hline
\end{tabular}




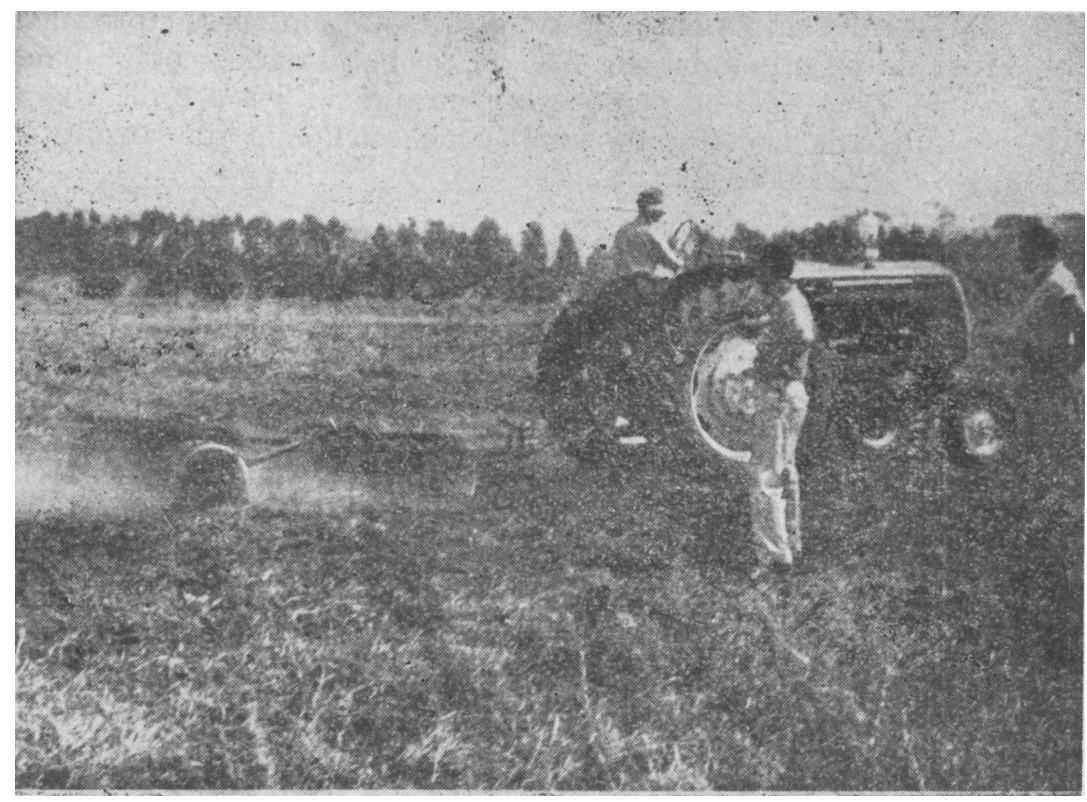

\section{ANALISE DOS DADOS *}

5.1 - Procurámos, de início, estudar grupados, os dados dos anos 50-51-52, e assim temos:

Em rama.

Análise da Variância

\begin{tabular}{l|c|r|r|r}
\hline \multicolumn{1}{c|}{ Causa de Variação } & G. L. & S. Q. & Q.M. & V \\
\hline Componente linear & 1 & $69.328,2$ & 69.328 & 1,94 \\
Componente quadrática & 1 & $9.491,64$ & 9.492 & 0,72 \\
Comp. de 3 e $4^{0}$ grau & 2 & $2.022,5 \%$ & 1.011 & 0,23 \\
\hline Tratamentos & $(4)$ & $(80.842,47)$ & - & - \\
Erro (a) & 15 & $276.734,83$ & 18.449 & - \\
\hline Anos & 1 & $13.801,94$ & 13.805 & 1,22 \\
Interações anos x trat. & 4 & $47.168,4 \%$ & 11.792 & 1.12 \\
Erro (b) & 15 & $139.853,02$ & 9.324 & - \\
\hline \multicolumn{1}{c}{ Total } & 39 & $558.403,73$ & - & - \\
\hline
\end{tabular}

* O Estudo Estatístico da experiência foi realizado pelo Dr. Frederico Pimentel Gomes, a quem apresentamos nossos agradecimentos. 
Apenas a componente linear dos tratamentos se aproxima do nivel de significância de $5 \%$ de probabilidade, pois para ela temos $\mathrm{V}=1,94$, au passo que o limite de $5 \%$ é 2,13 . Torios os demais ítens isolados na análise da variância são absolutsimente sem classificações.

\section{Em Casca.}

O mesmo esquema de análise foi usado neste caso, com os resuliados que constam do quadro seguinte:

\begin{tabular}{l|c|c|c|c}
\hline \multicolumn{1}{c|}{ Causa de Variação } & G. L. & S. Q. & Q.M. & V \\
\hline Componente linear & 1 & $21.945,31$ & 21.945 & $3,08^{* *}$ \\
Componente quadrática & 1 & $1.147,61$ & 1.148 & 0,70 \\
Compont. de 30 e 4 $4^{\circ}$ grau & 2 & $2.443,61$ & 1.222 & 0,73 \\
\hline T'ra tamentos & $(4)$ & $(25.536,53)$ & - & - \\
Erro (a) & 15 & $34.797,46$ & 2.320 & - \\
\hline Anos & 1 & $1.817,10$ & 1.817 & 0,97 \\
Interações anos x tratam. & 4 & $9.556,17$ & 2.389 & 1,12 \\
Erro (b) & 15 & $28.756,57$ & 1.917 & 1,12 \\
\hline \multicolumn{1}{c|}{ Total } & 39 & $100.463,83$ & - & - \\
\hline
\end{tabular}

Debulhado.

A análise da variância, dada a seguir, obedeceu ainda is mesmos moldes dos anteriores.

\begin{tabular}{|c|c|c|c|c|}
\hline Causa de Variação & G. L. & S. $Q$. & Q.M. & $\mathrm{V}$ \\
\hline $\begin{array}{l}\text { Componente linear } \\
\text { Componente quadrática } \\
\text { Compont. de } 3^{\circ} \text { e } 4^{\circ} \text { grau }\end{array}$ & $\begin{array}{l}1 \\
1 \\
2\end{array}$ & $\begin{array}{r}7.206,71 \\
38,54 \\
1.193,13\end{array}$ & $\begin{array}{r}7.207 \\
39 \\
597\end{array}$ & $\begin{array}{l}3,50 * * \\
0,26 \\
1,01\end{array}$ \\
\hline $\begin{array}{l}\text { Tratamentos } \\
\text { Erro (a) }\end{array}$ & $\begin{array}{l}(4) \\
15\end{array}$ & $\begin{array}{l}(8.438,98) \\
8.832,57\end{array}$ & $\overline{589}$ & $=$ \\
\hline $\begin{array}{l}\text { Anos } \\
\text { Interaçōes anos x tratam. } \\
\text { Erro (b) }\end{array}$ & $\begin{array}{r}1 \\
4 \\
15\end{array}$ & $\begin{array}{r}247,51 \\
5.621,67 \\
12.771,24 \\
\end{array}$ & $\begin{array}{r}248 \\
1.405 \\
851 \\
\end{array}$ & $\begin{array}{r}0,54 \\
1,28 \\
-\end{array}$ \\
\hline Total & 39 & $35 . \overline{911,91}$ & - & - \\
\hline
\end{tabular}

Também nêste caso é significativa a componente linear. A equação de regressão é

$$
y=45,25+1,90 x,
$$

onde y é a produção por parcela, em quilograma, e $x$ é a profundidade de aração em centímetros. 
Em Rama.

\begin{tabular}{l|c|c|c|c}
\hline \multicolumn{1}{c|}{ Causa de Variação } & G. L. & S. Q. & Q.M. & V \\
\hline Tratamentos & 6 & $196.365,08$ & 32.728 & $1,71^{*}$ \\
Êrro & 21 & $234.065,70$ & 11.146 & - \\
\hline \multicolumn{1}{c}{ Total } & 27 & $430.430,8$ & - & - \\
\hline
\end{tabular}

O efeito de tratamentos é, pois, significativo ao nível de $5 \%$. Agora poderemos repetir êsses tratamentos em dois grupos, um com as cinco profundidades menores de aradura e outro com as duas restantes.

Obtemos a seguinte análise.

\begin{tabular}{l|c|r|r|r}
\hline \multicolumn{1}{c|}{ Causa de Variação } & G. L & S. Q. & Q.M. & V \\
\hline Entre grupos & 1 & $98.700,17$ & 98.700 & $2,98^{* *}$ \\
Dentro do 10. grupo & 4 & $97.501,10$ & 24.375 & 1,48 \\
Dentro do 20. grupo & 1 & 163,81 & 164 & 0,038 \\
\hline Tratamentos & $(6)$ & $(196.365,08)$ & 32.728 & $1,71^{*}$ \\
Erro & 21 & $234.065,70$ & 11.146 & - \\
\hline \multicolumn{1}{c}{ Total } & 27 & $430.430,78$ & - & - \\
\hline
\end{tabular}

Verifica-se, pois, que os dois grupos diferem entre si, mas que, dentro de cada grupo, não há diferenças significativas. Como o primeiro grupo encerra exatamente os tratamentos estudados nos anos agrícolas 50-51 e 51-52, procuramos isolar os diversos componentes da regressão dentro dêsse grupo, com os resultados dados a seguir.

\begin{tabular}{l|c|c|c|c}
\hline Causa de Variação & G. L. & S. Q. & Q.M. & V \\
\hline Componente linear & 1 & $28.212,03$ & 28.212 & 1,59 \\
Componente quadrática $_{\text {Compont. de } 3^{\circ} \text { e 4 } 4^{\circ} \text { grau }}{ }^{\top}$ & 2 & $24.834,79$ & 24.835 & 1,49 \\
${\text { Dentro do } 1^{\circ} \text {. grupo }}^{\text {Deno }}$ & 4 & $44.454,28$ & 22.227 & 1,41 \\
\hline
\end{tabular}

Nenhum dêstes valores de $\mathrm{V}$ é significativo, embora sejam relativamente altos.

O que podemos concluir, pois, é que os tratamentos do primeiro grupo diferem significativamente dos tratamentos do segundo grupo. Não podemos chegar a nenhum resultado concludente quanto à variação dentro dos grupos. 


\section{Em Casca.}

A análise foi feita em moldes semelhantes ao do caso anterior.

\begin{tabular}{l|c|r|r|c}
\hline \multicolumn{1}{c|}{ Causa de Variação } & G. L. & S. Q. & Q.M. & V \\
\hline Entre grupos & & $18.438,91$ & 18.439 & $2,85^{* *}$ \\
Dentro do 10. grupo & 4 & $19.100,59$ & 4.775 & 1,45 \\
Dentro do 2. $2^{\circ}$ grupo & 1 & 174,84 & 175 & 0,28 \\
\hline Tratamentos & $(6)$ & $(37.714,34)$ & 6.286 & $2,76^{*}$ \\
Êrro & 21 & $47.753,31$ & 2.274 & - \\
\hline$\quad$ Total & 27 & $85.467,65$ & - & - \\
\hline
\end{tabular}

'Também neste caso os dois grupos diferem significativamente, mas dentro de cada grupo as diferenças não são significativas. Procuramos isolar os componentes de regressão no 1.0 grupo.

\begin{tabular}{l|c|c|c|c}
\hline \multicolumn{1}{c|}{ Causa de Variação } & G. L. & S. Q. & Q.M. & V \\
\hline Componente lin€ar & 1 & $7.806,44$ & 7.806 & 1,85 \\
Componente quadrática & 1 & $5.176,80$ & 5.277 & 1,52 \\
Compont. de 3" e 4. grau & 2 & $6.017,35$ & 3.009 & 1,15 \\
\hline Dentro do 10. grupo & 4 & $19.100,59$ & - & - \\
\hline
\end{tabular}
tes.

Também neste caso não são significativos êsses componen-

Debulhado.

A marcha da análise é inteiramente análoga à dos casos anteriores.

\begin{tabular}{l|c|r|r|l}
\hline \multicolumn{1}{c|}{ Causa de Variação } & G. L. & S. Q. & Q.M. & V \\
\hline Entre grupos & 1 & $2.365,26$ & 2.365 & $2,61^{*}$ \\
Dentro do $1^{\circ}$. grupo & 4 & $3.825,89$ & 956 & 1,66 \\
Dentro do 20. grupo & 1 & 171,12 & 171 & 0,70 \\
\hline Tratamentos & $(6)$ & $6.362,27$ & 1.060 & 1,75 \\
Erro & 21 & $7.308,17$ & 348 & - \\
\hline$\quad$ Total & 27 & $13.670,44$ & - & - \\
\hline
\end{tabular}


Isolemos agora os componentes de regressão dentro do 1.0 grupo obteremos :

\begin{tabular}{l|c|r|r|c}
\hline \multicolumn{1}{c|}{ Causa de Variação } & G. L. & S. Q. & Q.M. & V \\
\hline Componente linear & 1 & $1.357,23$ & 1.357 & 1,97 \\
Componente quadrática & 1 & $1.674,20$ & 1.674 & $2,19^{* *}$ \\
Compont. de $3^{\circ}$ e $4^{\circ}$ grau & 2 & 394.40 & 397 & 1,07 \\
\hline Trat. dentro do $1^{\circ}$. grupo & 4 & $3.825,89$ & - & - \\
\hline
\end{tabular}

A equação de regressão é

$$
y=1,4 i+7,73 x-0,219 x^{2},
$$

sendo y a produção por parcela em quilogramas, e $x$ a profundidade de aradura.

\section{CONCLUSŌES}

Com a análise dos resultados obtidos conclui-se :

6.1. - A análise estatística dos dados da experiência de 50-51 e 51-52, demonstra que à medida que aumenta a profundidade de aração, até o limite estudado, aumenta também a produção.

6.2 - Dêste resultado conclui-se que nêste tipo de solo é aconselhável fazer a aração profunda até, evidentemente, o limite máximo examinado $(25 \mathrm{~cm})$.

6.3 - Conforme se deduz da análise estatística, da primeira e segunda experiência, há uma regressão linear.

6.4 - A diferença foi pois significativa entre os dois grupos $(5$ a $25 \mathrm{~cm}$ e 30 e $40 \mathrm{~cm}$ ) da experiência $52-53$.

6.5 - Dentre o primeiro grupo (de 5 a $25 \mathrm{~cm}$ ), não houve diferença significativa para a rama e casca, mas houve uma regressão quatrática significativa para o caso de colheita em milho debulhado. 


\section{RESUMO}

A aradura é a principal das operaçōes agrícolas para o desenvolvimento das diversas culturas. A sua importância é conhecida desde as mais remotas eras. Assim, os romanos já tinham sua teoria sôbre aradura.

Desta forma o arado, a mais antiga das máquinas agrícolas, foi sempre motivo de atenção dos agricultores, fabricantes e técnicos em mecânica agricola. A sua evolução foi bastante grande.

O estudo do arado sob o ponto de vista agricola e econômico, para exata aplicação da máquina, nas diversas condiçōes de solo, é de máximo interêsse para a mecânica agrícola.

Assim sendo, para orientar a correta aplicação do arado, o que constitui a presente tese, foi experimentado num sulo arenoso, de caracteristicas mecanicas (areia total $\mathbf{7 5 , 7 \%}$, argila 13,5 e lôdo $10,8 \%$ ) a diversas profundidades de araçāo, $(5,10$, $15,20,25,30 \mathrm{~cm})$, plantando nos mesmos, milho para verificar - efeito na produçấo. Num terceiro ano de experiếncia, foi realizada uma experiência a mais, isto é, uma subsolagem a $40 \mathrm{~cm}$.

Foi plantado milho nos canteiros assim trabalhados, e que eram repetidos em número de 4 , porque o milho é uma cultura muito frequente e de fácil contróle.

As experiências com as diversas profundidades, demostraram que nestas condiçöes de solo, à medida que aumenta a profundidade, aumenta também a produção.

Do exposto, conclui-se pela experimentação que para êsse solo é aconselhável : fazer o arado trabalhar a maior profundidade em que comumente é empregado até o limite de $25 \mathrm{~cm}$, que foi o valor máximo examinado.

\section{SUMMARY}

No matter what crop is concerned, plowing the soil is the main agricultural practice. Its importance is well known since many centuries ago: suffices to say that the Romans before Christ already had a theory on plowing the land.

Thus, the plow, the oldest agricultural implement, has always attracted the attention of farmers, engineers and people engaged on agricultural mechanics. For this reason, its evolution was remarkable. 
The study of the plow, under both an agricultural and an economic point of view, is of great interest to agricultural mechanica, since on such a kind of research is based the best meihod of application of the plow.

The present paper deals with an experiment carried out to obtain data on the use and effect of plowing as related to different depths of doing it. The soil worked out presented the following characteristics: total sand $-75.7 \%$, clay $-13.5 \%$, silt - $10.8 \%$; hence, it is a sandy soil. Plowing was made at the following depths : $5,10,15,20,25$, and $30 \mathrm{~cm}$. in the first iwo years; in the third year, another depth was included, that is, $40 \mathrm{~cm}$., which corresponds to an under-plowing. The field trial was conducted with four replicates throughout, plots $50 \times 20 \mathrm{~m}$. being used. Corn was planted to find out the effects of the depth of plowing on such a crop.

The following conclusions can be drawn:

1. on the experimental conditions, yield was directly proportional to the depth of plowing; in other words, the deeper the plow works, the best is the yield therein obtained;

2. it is therefore suggersted that on soils similar to this experiment's it is advisable to plow deeper than usual; a working depth of $252 \mathrm{~cm}$. is recommended.

\section{BIBLIOGRAFIA}

CONTI, M., 1942 - Tratado de Mecanica Agricola, 2a. Parte Bartolomé U. Chiesino, Buenos Aires.

FORD, H. - "Minha Vida e Minha Obra" - Editôra Melhoramentos - São Paulo.

RANZANI, G., 1956 - Levantamento da Carta de Solos da Secção Técnica "Química Agrícola" da Escola Superior de Agrịcultura "Luiz de Queiroz" - Editôra Jornal de Piracicaba.

Tractor Red Book, 1952 - Implement \& Tractor, Official Nebraska Tests - Kansas City, U.S.A. 
